\title{
Power Processing and Flow Control for a 100kW Hall Thruster System
}

\author{
Erich Soendker ${ }^{1}$, Sam Hablitzel ${ }^{2}$, Artie Tolentino ${ }^{3}$, Benjamin Welander ${ }^{4}$, \\ Sarah Shark $^{5}$, May Allen ${ }^{6}$, and Jerry Jackson ${ }^{7}$ \\ Aerojet Rocketdyne, Los Angeles, CA and Redmond, WA, United States \\ Eric Pencil ${ }^{8}$ \\ NASA Glenn Research Center, Cleveland, OH, United States
}

\begin{abstract}
Aerojet Rocketdyne's NextSTEP program is developing and demonstrating a $100 \mathrm{~kW}$ Electric Propulsion (EP) system, the XR-100, which includes a modular power processing unit and modular xenon feed system to operate a Nested Hall Thruster (NHT) designed for powers up to $200 \mathrm{~kW}$. The NextSTEP system is intended for use on large scale cargo transportation to support human missions to the Moon and Mars, which require very highpower Solar Electric Propulsion (SEP) systems operating between 200 and $400 \mathrm{~kW}$. The three-year program objective is to operate the integrated EP system continuously at $100 \mathrm{~kW}$ for 100 hours, advancing this very high-power EP system to Technology Readiness Level (TRL) 5. In order to process the power and control propellant flow for this high-power system, Aerojet Rocketdyne has developed a modular concept for the Power Processing Units (PPUs) and Xenon feed system. The program has completed testing of critical elements of the PPU and feed system with a thruster simulator. Design upgrades to demonstrate the TRL 5 capabilities are underway. This paper will present an overview of the program and system design approach, the high power XR-100 capabilities of the PPU and feed system, and the latest test results for the $100 \mathrm{~kW}$ EP system demonstration program. In order to successfully execute this contract, there is a close collaboration between the teammates at Aerojet Rocketdyne (AR), the University of Michigan (UM), the NASA Jet Propulsion Laboratory (JPL), and the NASA Glenn Research Center (GRC).
\end{abstract}

\section{Nomenclature}

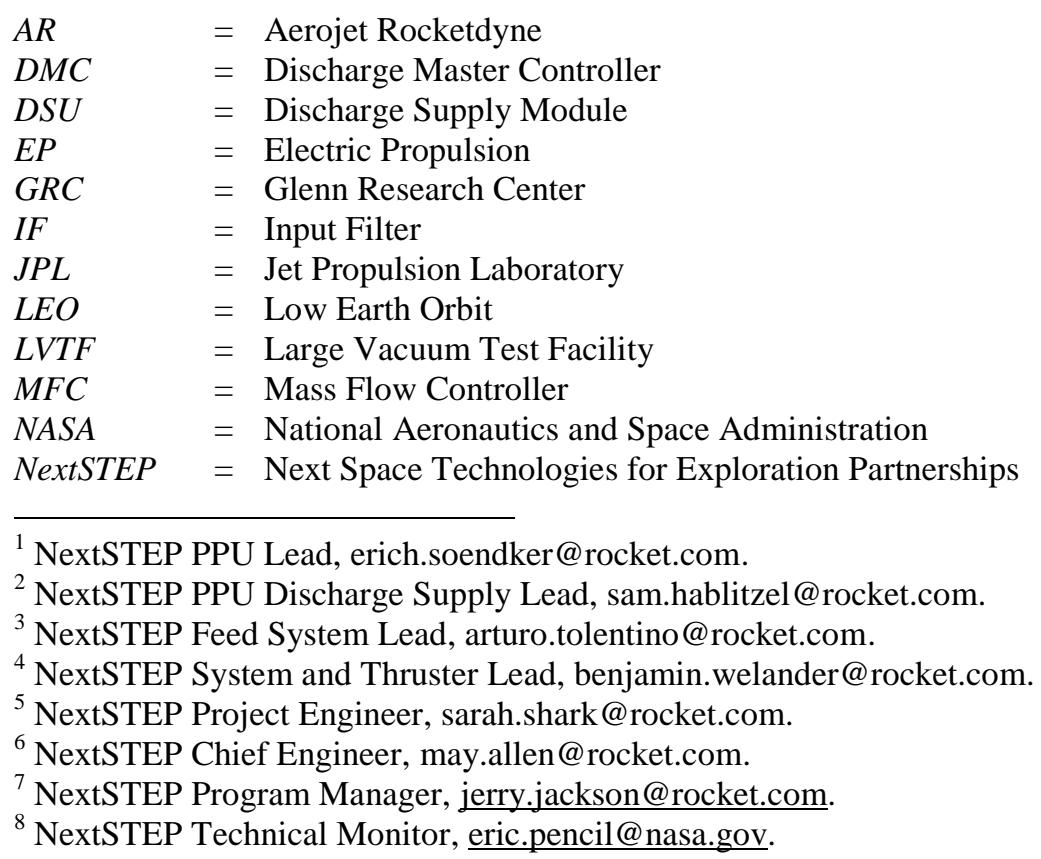




$\begin{array}{ll}\text { NHT } & =\text { Nested Hall Thruster } \\ \text { OFB } & =\text { Output Filter Board } \\ P E P L & =\text { Plasmadynamics and Electric Propulsion Laboratory } \\ P F C V & =\text { Proportional Flow Control Valves } \\ P M & =\text { Power Modules } \\ P M U & =\text { Propellant Management Unit } \\ P P U & =\text { Power Processing Unit } \\ S E P & =\text { Solar Electric Propulsion } \\ \text { SFC } & =\text { System Flow Controller } \\ T R L & =\text { Technology Readiness Level } \\ V F & =\text { Vacuum Facility } \\ U M & =\text { University of Michigan } \\ U S A F & =\text { United States Air Force }\end{array}$

\section{Introduction}

$\mathbf{I}^{\mathrm{N}}$ $\mathrm{N}$ recent years, high power Electric Propulsion (EP) systems ( $>100 \mathrm{~kW}$ ) have been identified as a high-priority echnology for development, as discussed in the 2012 NASA Space Technology Roadmaps and Priorities. Missions to transport astronauts or the infrastructure needed to support manned mission (e.g., SEP cargo tug) drives the requirement for higher-power EP than currently exists. This is where the NASA's Next Space Technologies for Exploration Partnerships (NextSTEP) demonstration of a $100 \mathrm{~kW}$ Nested Hall Thruster becomes a key enabling technology. Ref. [1] The NextSTEP program was awarded to the Aerojet Rocketdyne (AR) team in January of 2016. Under the contract, the Aerojet Rocketdyne team will complete the development of the XR-100, a $100 \mathrm{~kW}$ Hall Thruster System, including: a $200 \mathrm{~kW}$ thruster, critical elements of a $100 \mathrm{~kW}$ modular Power Processing Unit (PPU), and elements of the modular Xenon feed system. The PPU elements are the first flight-like design to run a high power EP thruster meeting the challenging thermal and performance goals. The modular feed system is an innovative and cost-effective design developed internally at AR that operates in a closed-loop fashion with the PPU and thruster. The contract includes system integration testing and will culminate with a NASA TRL 5 demonstration of a $100 \mathrm{~kW}$ system for 100 hours at thermal steady-state. The modular nature of these technologies enables system scalability to $200 \mathrm{~kW}$ with the current thruster design as well as multi-megawatt power levels with a scaled thruster design while meeting the long-term system performance and mass objectives of the project.

\section{Program Overview}

The awarded NextSTEP program is a three-year program which began in 2016. The program objective is to develop the XR-100 system to TRL 5. Ref. [2] The XR-100 components have varying levels of maturity at the start of the program. The X3 Nested Hall Thruster (NHT) was already near TRL 5 via programs supported by University of Michigan's (UM) Plasmadynamics and Electric Propulsion Laboratory (PEPL), Air Force Research Laboratory (AFRL), NASA's Glenn Research Center (GRC), and Jet Propulsion Laboratory (JPL). Ref. [3,4] The thruster work on NextSTEP includes design updates as needed, further development of the cathode, and updated thermal models. Thruster design work is supported primarily by UM PEPL while cathode development and modeling is primarily supported by JPL. Flight-like elements of the PPU were developed at AR to operate the high power NHT and to control the xenon feed system. The program focused on the challenges of the Discharge Supply Unit (DSU) and the closed-loop system control of the NHT and MFC. The modular Xenon feed system consists of a Propellant Management Unit (PMU) and modular Mass Flow Controllers (MFCs). The same technology is utilized in both units to proportionally control flow as needed. The MFC valves have a wide flow range of operation and include telemetry for closed-loop control.

The modular PPU and MFC allow for scaling to $200 \mathrm{~kW}$ with the current thruster design without developing new technology. Propellant is fed from the tanks into the PMU, which includes the latch valves and filtering required to meet range safety and mission assurance requirements. The PMU conditions propellant that is fed into the MFCs, which in turn allow for flow rate tailoring for each Hall thruster channel. This allows flow to be optimized channel by channel to provide a range of operation. The MFC design is modular and easily scaled for larger systems. The baseline propellant is xenon gas, which has been shown to be safe, dense, and long-term storable as compared to cryogenic propellants such as hydrogen. The modular PPU approach enables a distributed PPU architecture with 
scalability to higher powers that allow vehicle designers the flexibility to spread the PPU module mass and thermal loads for optimal placement on spacecraft, even for spacecraft with different physical designs.

In the first year, the team designed, built, and bench tested the PPU elements and the MFC module. The MFC was also operated via closed-loop control using the PPU system control circuit. This hardware was updated in year 2 with all the manufacturing and testing lessons learned, and additional hardware was built to support the year 2 objectives. These objectives included low power system operation and demonstration of scalability to $100 \mathrm{~kW}$. The current (year 3) objective is to operate the system at 100kW. Details of the technical objectives and status are in the remainder of this paper.

\section{System Architecture and Test}

The XR-100 system configuration, which will use a PPU capable of delivering $100 \mathrm{~kW}$ of power to the NHT and of providing closed loop control of the mass flow controllers, is shown in Figure 11. The XR-100 feed system consists of a PMU and modular MFCs which are based on Aerojet Rocketdyne proprietary designs. The specific goals of the NextSTEP project are shown in Table 1. Thrust is included in the table for information purposes but is not a program goal. Additionally, the X3 is capable of operating over a range of discharge voltages of 200 to $800 \mathrm{~V}$. This architecture allows for unprecedented throttleability based on flight proven technology.

Hall systems present a stable DC electrical load to the spacecraft power system that can be gradually ramped up to avoid large power transients. The XR-100 system is being designed to operate efficiently between $25 \mathrm{~kW}$ and $100 \mathrm{~kW}$. Like other Hall thrusters, the X3 requires only propellant, power, and enough

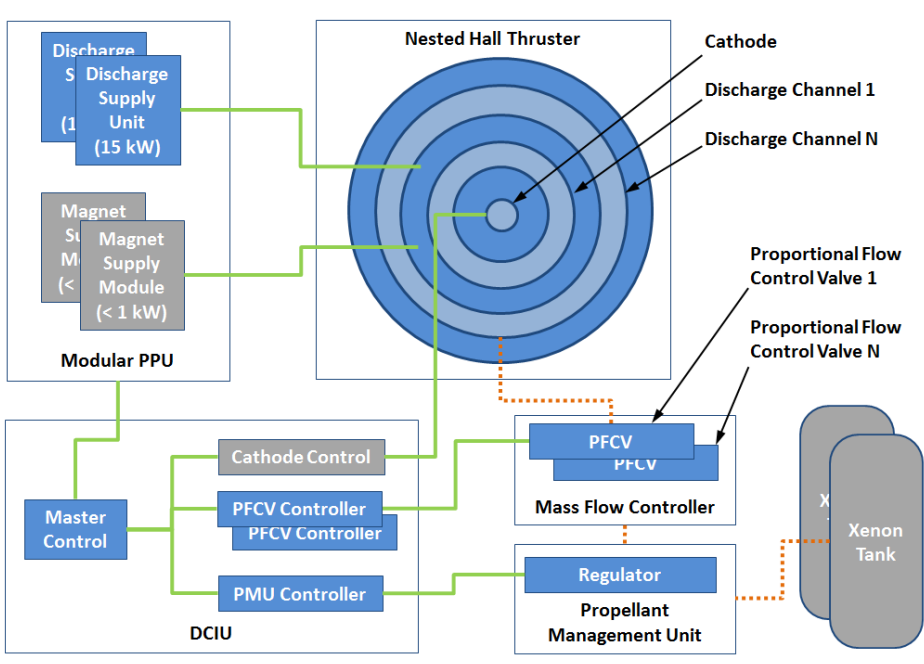

Figure 1. Block diagram of XR-100 system architecture showing modularity chosen to take advantage of NHT wide throttle range. Blue blocks are being developed as part of the NextSTEP program.

heat during periods of eclipse to keep components above their qualified temperatures. The NHT passively radiates all of the heat generated during operation and requires no active or conductive cooling. Because the NHT operates predominately as a DC electric load, the thruster may be located several meters away from the PPU and MFC.

Table 1. NASA NextSTEP Program Objectives

\begin{tabular}{|l|l|l|}
\hline Metric & XR-100 Objective \\
\hline Requirement & TRL 5 demonstration power & $100 \mathrm{~kW}$ \\
\cline { 2 - 3 } & TRL 5 steady state operation time & $100 \mathrm{~h}$ \\
\hline \multirow{5}{*}{ Objective } & Specific Impulse & $\sim 2,000$ to $~ 5,000 \mathrm{~s}$ \\
\cline { 2 - 3 } & Thrust per thruster & $>5 \mathrm{~N}$ \\
\cline { 2 - 3 } & In-space lifetime capability & $>50,000 \mathrm{~h}$ \\
\cline { 2 - 3 } & Operational lifetime capability & $>10,000 \mathrm{~h}$ \\
\cline { 2 - 3 } & System efficiency & $>60 \%$ \\
\cline { 2 - 3 } & Power per thruster & $100 \mathrm{~kW}$ \\
\cline { 2 - 3 } & System $\mathrm{kg} / \mathrm{kW}$ & $<5 \mathrm{~kg} / \mathrm{kW}$ \\
\hline
\end{tabular}

The NextSTEP program includes a series of design, build and test iterations that methodically grow the system capability and demonstrate successively more challenging test objectives. The first system test, following extensive component level tests, was performed at $10 \mathrm{~kW}$. Ref. [5] The program objective is to perform a $100 \mathrm{~kW}$ system test in the November 2018 timeframe. 


\section{Power Processing Unit}

The NextSTEP PPU is required to power three thruster channels (inner, middle and outer) providing $15 \mathrm{~kW}, 30$ $\mathrm{kW}$, and $55 \mathrm{~kW}$ respectively for a total of $100 \mathrm{~kW}$. While the flight PPU will incorporate low power supplies for the cathode, heaters, and magnets, the current focus of the NextSTEP PPU effort is the discharge supply since this is the most challenging part of the PPU. The discharge supply uses a modular design that can support multiple configurations for a single DSU or multiple DSUs in parallel and power each of the 3 NHT channels (see Figure 2). This architecture offers greater flexibility and can easily expand to higher power levels.

Each DSU consists of a Discharge Master Controller (DMC), input filter (IF), output filter board (OFB), and four power modules (PM). The PMs each provide up to $400 \mathrm{~V}$ and $4 \mathrm{~kW}$ of power and can be configured in parallel mode or a series/parallel mode. The configuration selection is accomplished with selection switches on the OFB. The DMC communicates with a laboratory control computer (Spacecraft C\&DH simulator), receiving set point command and providing telemetry for display and data logging. The input filter has a disconnect switch to provide a controlled power sequence during multiple DSU configuration testing. Each DSU is capable of delivering $16 \mathrm{~kW}$ of power from an input voltage range of $95 \mathrm{~V}$ to $140 \mathrm{~V}$, which provides some margin to the $15 \mathrm{~kW}$ requirement. The controls architecture was devised to allow multiple DSUs to operate in parallel on a single thruster anode channel with the returns tied to one common cathode. The DSU is capable of delivering $15 \mathrm{~kW}$ at $350 \mathrm{~V}-400 \mathrm{~V}$ to maximize thrust or $700 \mathrm{~V}-800 \mathrm{~V}$ to maximize ISP.

A controller for the MFC valves was developed to provide closed-loop control for the xenon flow and discharge current for each of the 3 discharge anode channels and the cathode. This combination of hardware and control firmware is known as the System Flow Controller (SFC). The SFC is not only capable of controlling the valves, but also coordinates the flow rates as needed to smoothly operate a thruster through start up, steady state, fault and shutdown conditions. This controller will also control the same type of proportional flow control valves that are to be used in the Propellant Management Unit (PMU) using the same hardware control circuitry.

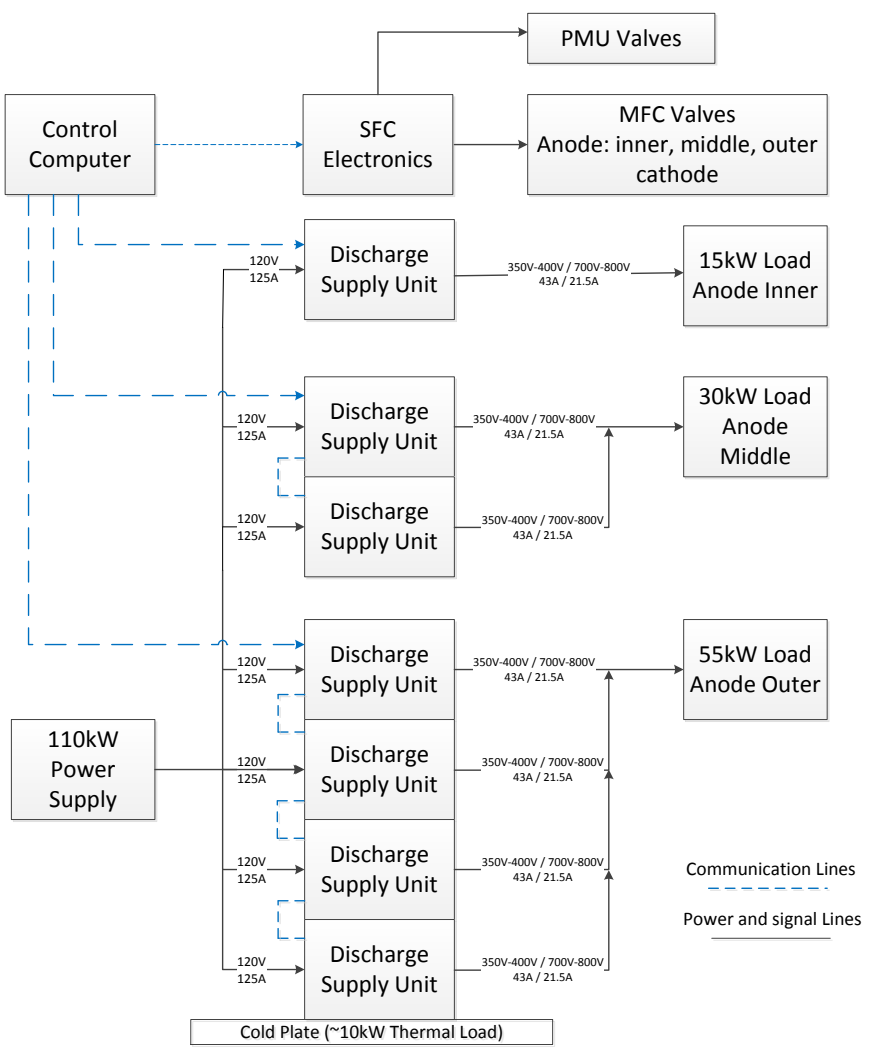

Figure 2. 100kW System Configuration

During the $1^{\text {st }}$ year, a single DSU and SFC designs were built and tested with the Nested Hall Thruster at the University of Michigan. The testing successfully verified DSU operation at $10 \mathrm{~kW}$ at output voltages between $400 \mathrm{~V}$ and $800 \mathrm{~V}$. The MFC and SFC provided excellent closed-loop control of flow and discharge current. After this successful demonstration, lessons learned were incorporated into the design to build the $100 \mathrm{~kW}$ EP system. Bench testing of the final design was completed, and the hardware supported a $10 \mathrm{~kW}$ system test. 
A single DSU was demonstrated to operate with thruster and with the following efficiency when tested at the University of Michigan. These results are shown in Table 2.

Table 2. Demonstrated DSU efficiency while operating the Nested Hall Thruster

\begin{tabular}{|c|c|c|c|c|c|c|}
\hline $\begin{array}{c}\text { Input } \\
\text { Voltage }\end{array}$ & $\begin{array}{c}\text { Input } \\
\text { Current }\end{array}$ & $\begin{array}{c}\text { Calculated } \\
\text { Input } \\
\text { Power }\end{array}$ & $\begin{array}{c}\text { Output } \\
\text { Voltage }\end{array}$ & $\begin{array}{c}\text { Output } \\
\text { Current }\end{array}$ & $\begin{array}{c}\text { Calculated } \\
\text { Output } \\
\text { Power }\end{array}$ & Efficiency \\
\hline $107.0 \mathrm{~V}$ & $99.6 \mathrm{~A}$ & $10,657.2 \mathrm{~W}$ & $400.4 \mathrm{~V}$ & $25.56 \mathrm{~A}$ & $10,234.2 \mathrm{~W}$ & $96.03 \%$ \\
\hline $103.6 \mathrm{~V}$ & $103.8 \mathrm{~A}$ & $10,753.7 \mathrm{~W}$ & $400.4 \mathrm{~V}$ & $25.94 \mathrm{~A}$ & $10,386.3 \mathrm{~W}$ & $96.58 \%$ \\
\hline $104.0 \mathrm{~V}$ & $85.6 \mathrm{~A}$ & $8,902.4 \mathrm{~W}$ & $602.0 \mathrm{~V}$ & $14.37 \mathrm{~A}$ & $8,650.7 \mathrm{~W}$ & $97.17 \%$ \\
\hline $105.8 \mathrm{~V}$ & $97.2 \mathrm{~A}$ & $10,283.8 \mathrm{~W}$ & $705.6 \mathrm{~V}$ & $14.16 \mathrm{~A}$ & $9,991.3 \mathrm{~W}$ & $97.16 \%$ \\
\hline $105.9 \mathrm{~V}$ & $97.0 \mathrm{~A}$ & $10,272.3 \mathrm{~W}$ & $800.0 \mathrm{~V}$ & $12.50 \mathrm{~A}$ & $10,000.0 \mathrm{~W}$ & $97.35 \%$ \\
\hline
\end{tabular}

\section{The Power Module PM Architecture}

The NextSTEP EP power string is able to achieve an extremely wide range of output power ranging from $55 \mathrm{~kW}$ down to $1.5 \mathrm{~kW}$ for a single thruster channel of the Nested Hall Thruster. Lower power configurations are also available for lower power thruster channels in increments of $15 \mathrm{~kW}$. The architecture of the PPU network allows this wide range of power output to be achieved by using multiple instances of the AR designed Power Module DCDC converter and a digital control architecture.

Using multiple instances of the same Power Module has led to a robust 4kW 150-400V power module design which has been demonstrated to achieve between 96-97\% efficiency. This $4 \mathrm{~kW}$ Power module is a building block which can be placed in series or parallel with other Power Modules to achieve higher discharge voltages and higher discharge currents. The high efficiency is not lost when Power Modules are combined to achieve higher total system power. The $4 \mathrm{~kW} 150 \mathrm{~V}-400 \mathrm{~V}$ output power level is based on how much power can be processed through space grade components. The $4 \mathrm{~kW}$ level is roughly the peak efficiency of state-of-the-art space grade components. Higher power levels introduce challenges of limitations of space grade electronic components and dimensioning returns in efficiency. The single design $4 \mathrm{~kW}$ power module design reduces the complexity on component engineering and power electronics design.

A

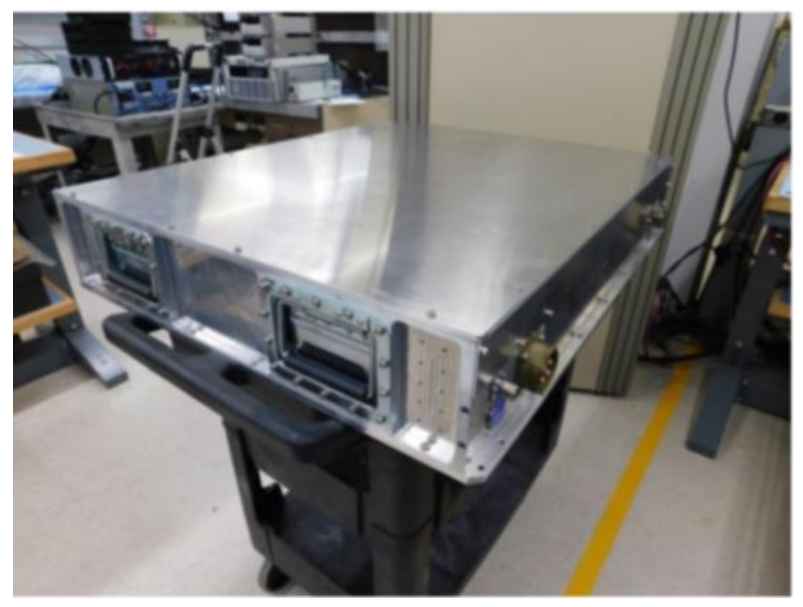

B

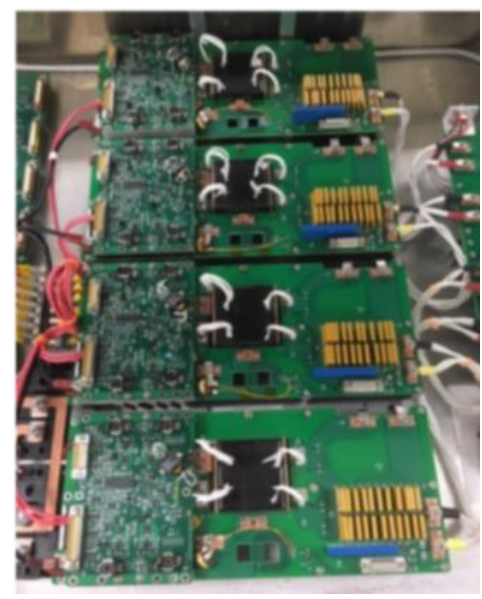

Figure 3. A) Discharge Supply Unit Assembly

B) Four Power Modules (PM) inside a Discharge Supply Unit

Although the component and hardware design is made easier through a modular approach, the control system becomes more challenging by requiring multiple power modules to generate a single stable discharge voltage. When more than one discharge supply unit is connected in parallel (NextSTEP connects 4 DSU in parallel), the controls problem increases in complexity. NextSTEP control architecture is developed for this purpose using a 
digital control architecture. The digital architecture replaces a high number of components and complex interconnections between PPU to share analog control information with a simple digital communication interface.

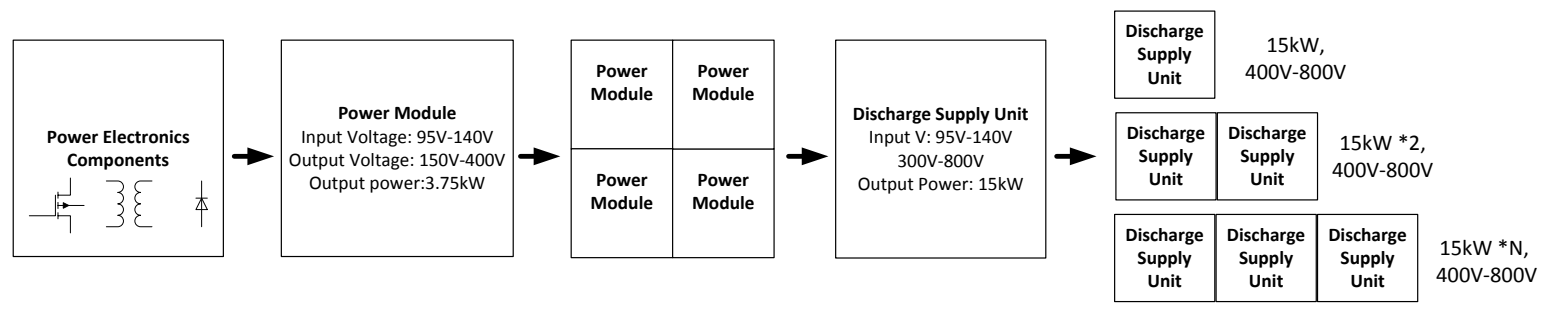

Figure 4. Building Blocks of the Aerojet Rocketdyne high power EP PPU architecture

Figure 5 shows the architecture and strategy which enables a single design power module to be expanded to provide over $100 \mathrm{~kW}$ to a thruster channel. This design strategy for a single Discharge Supply Unit was demonstrated at the University of Michigan with the Nested Hall Thruster. Figure 6 shows the output voltage and output current output by each Power Module. This test data is telemetry data from the DSU controller and was taken with the DSU in the high voltage mode power the NHT at University of Michigan. The total discharge voltage and current delivered to the thruster in this mode is equal to $2 \mathrm{x}$ the Power module voltages and currents shown in the Figure 5. Figure 5(A) and Figure 5(B) demonstrates equally power sharing during transient voltage steps. Figure 5(C) and Figure 5(D) demonstrates equal power sharing during transient current steps.
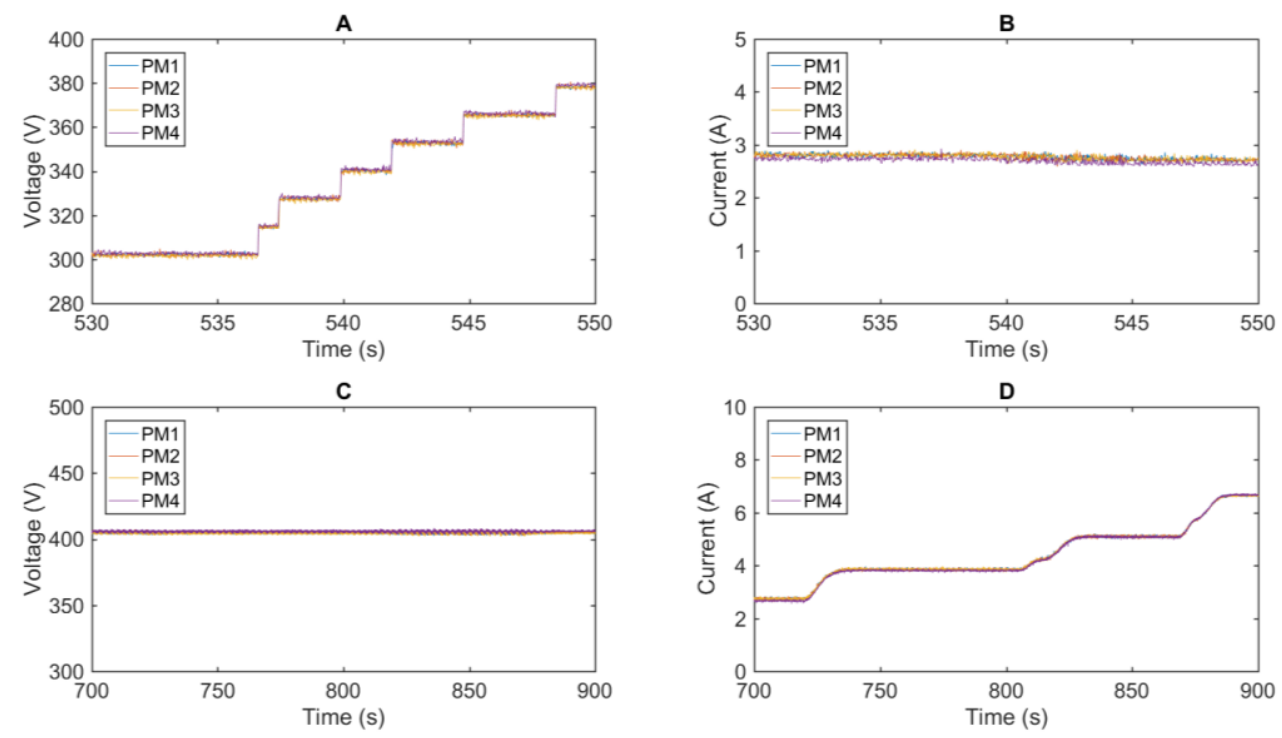

Figure 5. Power sharing between Power Modules within a Discharge Supply Unit power thruster

Similar to the hardware development, the firmware development has been developed in a modular fashion. Although the controls problem may be complex, it is solved mainly through the repetition of digital control modules. Between the $55 \mathrm{~kW}, 30 \mathrm{~kW}$ and $15 \mathrm{~kW}$ operating conditions for the various discharge outputs in the NHT system, the control code is very much the same.

\section{Feed System - Mass Flow Controller and Propellant Management Unit}

The function of the NextSTEP Flow Control System is to deliver xenon from the high-pressure xenon tanks to each of the five channels in the NHT. This feed system has two major modules - a Propellant Management Unit 
(PMU) and a Mass Flow Controller (MFC). The PMU provides both pressure regulator and service valve functions. The MFC provides proportional flow control to three anode and two cathode channels. A schematic of this system is shown in Figure 6.

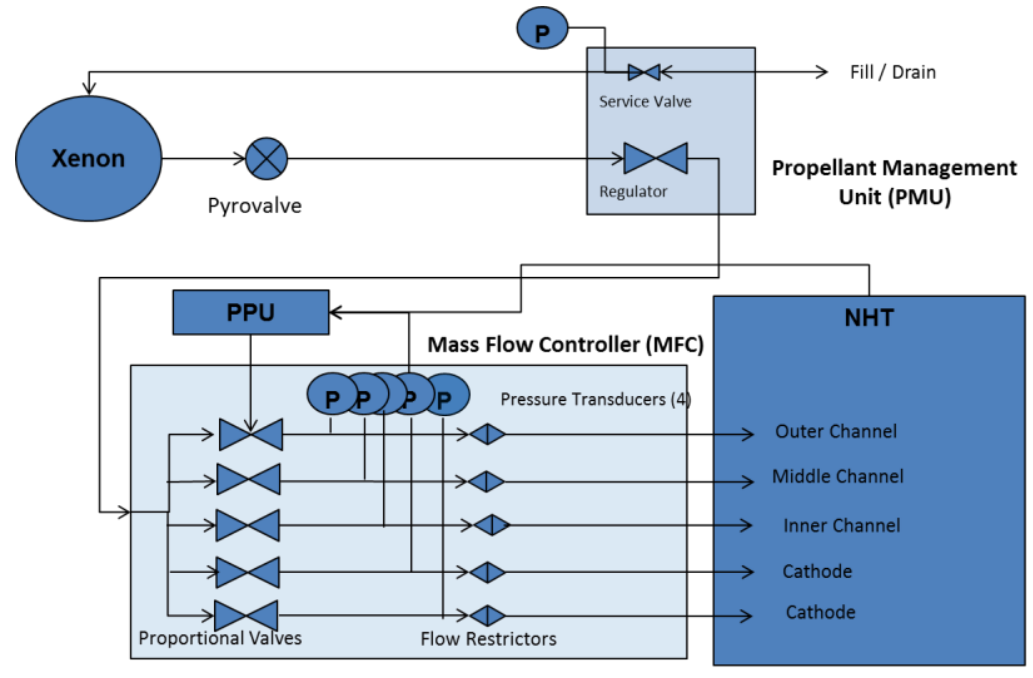

Figure 6. NextSTEP Feed System

The pressure regulator in the PMU and the proportional flow control valves (PFCV) in the MFC are controlled by a System Flow Control Board within the PMU which continually adjusts the input current to the PFCV until the desired feed pressure and flow rate are met. A cascade control system is used wherein the pressure feedback from the MFC (or PMU) is used to get the flow rate to within range of the target set-point after which the thruster's discharge current is used for precise flow rate control. This cascade flow control schematic is shown in Figure 7.

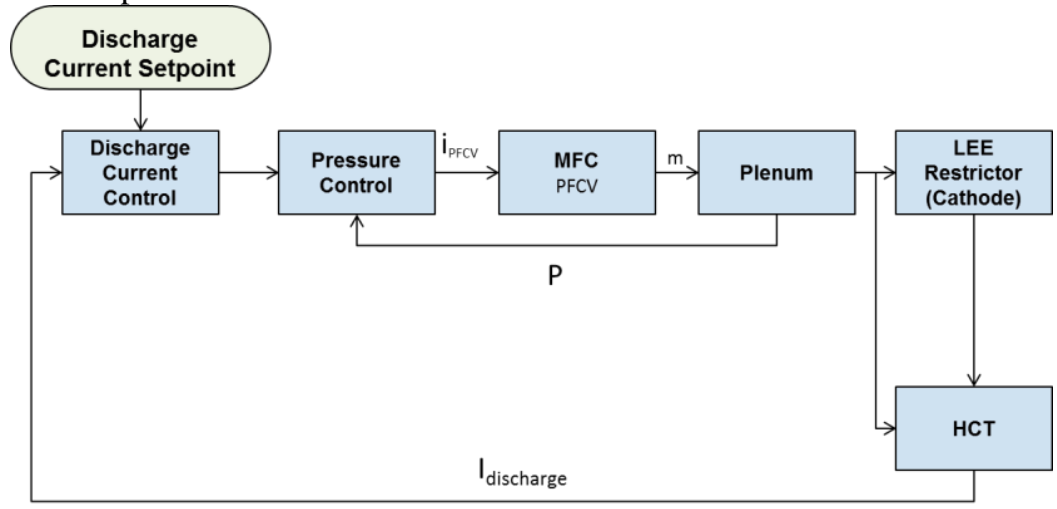

Figure 7. NextSTEP Discharge Current and Flow Control Loop

\section{Proportional Flow Control Valves}

The PFCV's are voice-coil type linear actuators in which the magnetic forces acting on the valve's moving element are directly proportional, in direction and magnitude, to the input current. The magnetic design of this valve is such that the valve body, which is typically an expensive weldment consisting of several magnetic and nonmagnetic materials, need not be magnetic at all. For NextSTEP, these PFCV's utilize valve bodies made out of a single material, which is non-magnetic and light.

The forces generated by the valve coils are directly (linearly) proportional to the current applied to the coils. The valve actuation forces are bi-directional. While the valves will close upon removal of current, the application of a reverse current will also close a valve and apply the force in the opposite direction. This offers the potential for flow control in an alternating current mode or for active control of leakage under a vibration or shock environment.

Mass Flow Controller (MFC) 
The MFC is a five-valve module that controls the flow to five flow channels within the NHT. This MFC can be seen in Figure 8.

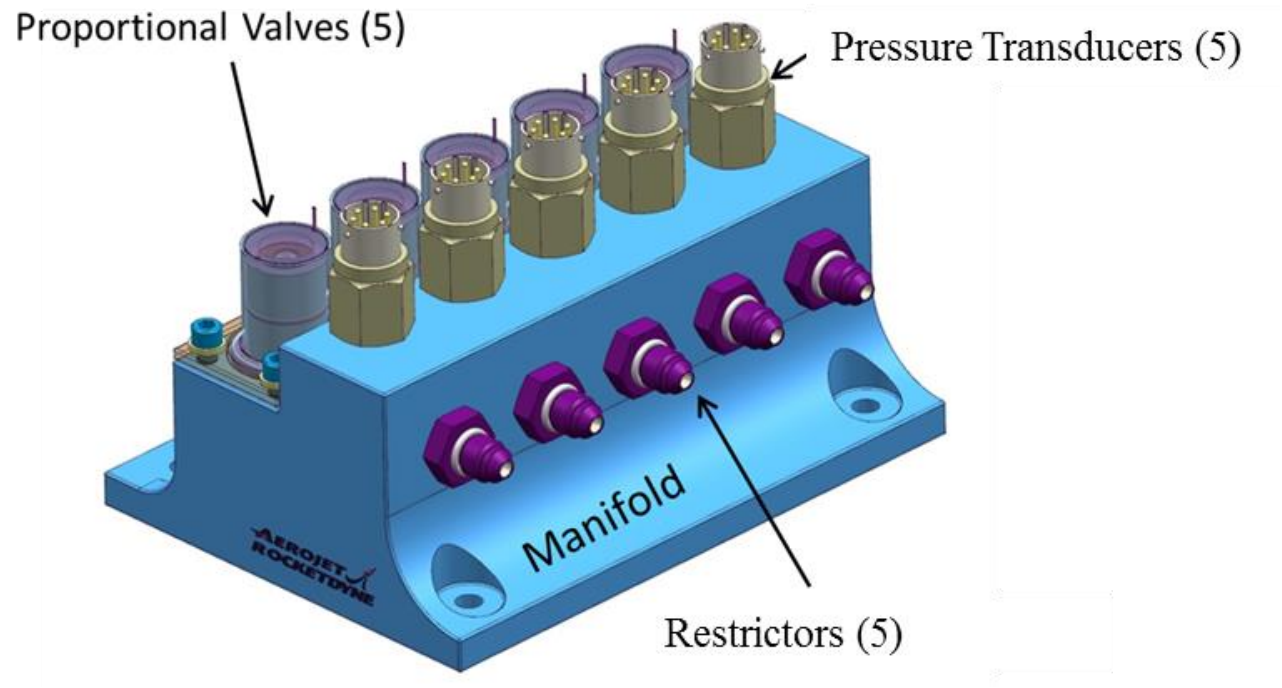

Figure 8. Five-Valve Mass Flow Controller

The MFC has five identical PFCV's fed by a single inlet. Each flow circuit contains one PFCV, one absolute pressure transducer and one restrictor. Each PFCV controls the pressure behind each circuit's restrictor to achieve the target flow rate. Each restrictor is sized so that a given backpressure is achieved at the target flow rate at the accuracy desired by the system.

The transducer can also feed pressure telemetry to the PPU for flow rate measurements. Like AEPS, such a system will require calibration at the component level to relate flow rate to the voltage outputs. RTD's can be used at the locations of the restrictors to provide temperature telemetry for the flow rate calibration.

The design approach of the PFCV was verified through a bench test during the first year which demonstrated the design concept and its performance. This bench unit and test set-up are shown in Figure 9(A). During the bench testing, the PFCV was tested under both open loop and closed loop control. Closed loop control was achieved by a simple flow control board with highly successful results as shown in Figure 9(B).
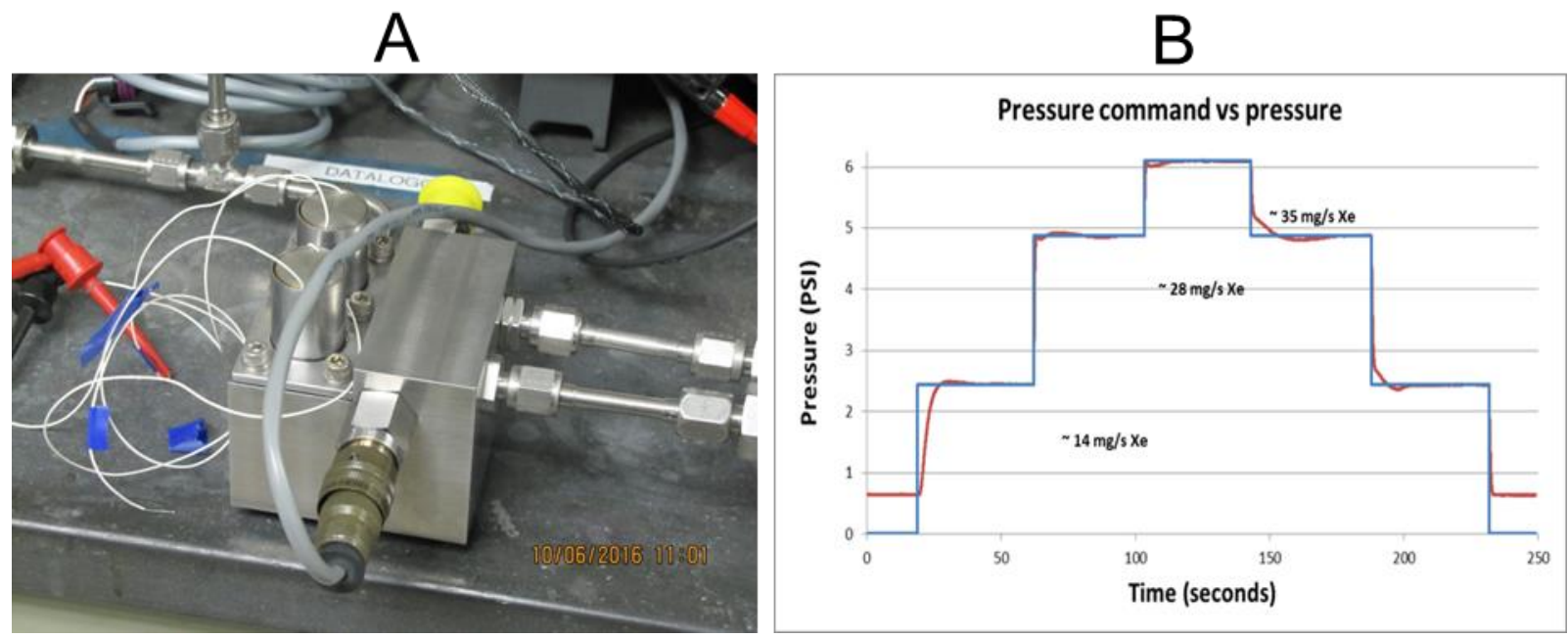

Figure 9. Year 1 bench demonstration unit (A) and closed loop control results with SFC prototype (B) 
The success of the first year resulted in the fabrication for the five-valve unit in Year 2 with very little modifications. The five-valve unit was integrated with the PPU and the thruster in the $10 \mathrm{~kW}$ test also with successful flow control results. The MFC is designed to provide a combined flow rate of as high as $250 \mathrm{mg} / \mathrm{s}$.

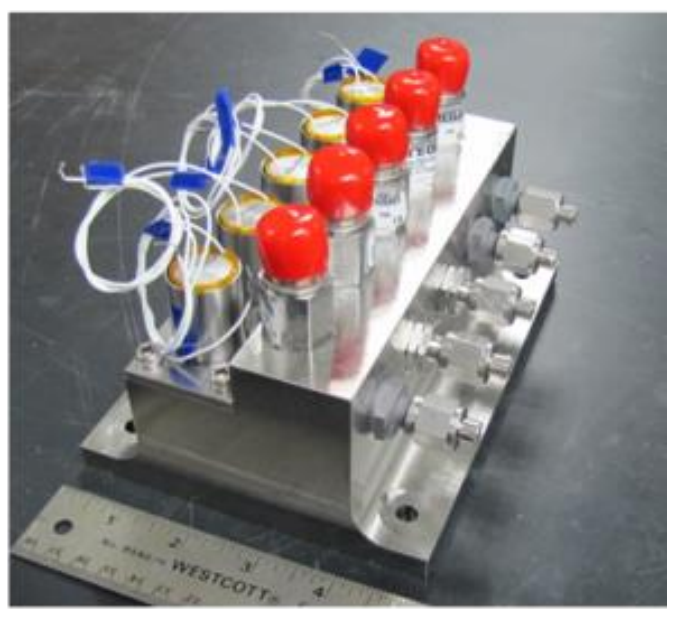

Figure 10. Five-Valve MFC

\section{Propellant Management Unit}

The PMU has two functions performed by identical PFCV's. One PFCV serves as a fill and drain valve while the other serves as a pressure regulator. The pressure regulator operates in exactly the same way as the MFC PFCV's. This valve is a normally closed valve and served to isolate the system prior to activation. The valve can operate in either "bang-bang" mode or proportional mode. Since the regulator's performance is controlled by a flow control board, the mode of operation and the outlet pressure can be modified at any time. The PMU PFCV's are nearly identical in design and function to the MFC PFCV's Unlike the MFC, the PMU regulator will be operated only in the pressure control mode.

\section{Design to Cost as a Primary Objective}

Both PMU and MFC were designed with low cost as a primary objective. Design features were selected to maximize the use of lathe and drill machining with relatively generous tolerances. As much as possible, special processes were avoided and the design features where chosen to eliminate the need to any kind of precision adjustment during assembly. The MFC and PMU can be assembled at a single station eliminating costly parts movement in the assembly area. The PMU and the MFC drawing trees are flat with no separate assembly levels for valves.

\section{SFC Electronics and Controls Architecture}

The flow rate and thrust control of the Nested Hall Thruster with the center mounted cathode and three anode rings provides another challenge to the PPU electronics. In order to maintain proper thruster control five proportional control valve positions must be continually adjusted by sending a current signal to each valve coil. The PPU's System Flow Controller (SFC) is in charge of reading critical flow feedback, performing closed loop control operations on thrust and flow rate and generating that current signals that drive the PFCV valves. In addition to the thruster flow rate control, the SFC also is in charge of controlling two additional PFCV which are used in the PMU system.

Circuitry has been developed to provide the valves with the appropriate constant current which can range from 0$300 \mathrm{~mA}$ and can be adjusted in minimum increments of $0.1 \mathrm{~mA}$. This range of current has been scaled for the mechanical properties of the MFC and PMU valves, but could be easily adjusted to support smaller or larger current ranges. This current set point is adjusted by the SFC FPGA which can communicate the set point to the analog circuitry through a digital to analog converter. The coil current is also measured and collected as telemetry for health monitoring purposes. A pressure transducer which is located between the PFCV valve and a flow restrictor 
on each valve is read by the PPU. From this pressure reading a corresponding flow rate can be calculated. However, for ground testing performed thus far, a flow rate has been determined by doing a direct calibration between measured flow rate and measured pressure. An example of the SFC performing closed loop flow control is shown in Figure 11.

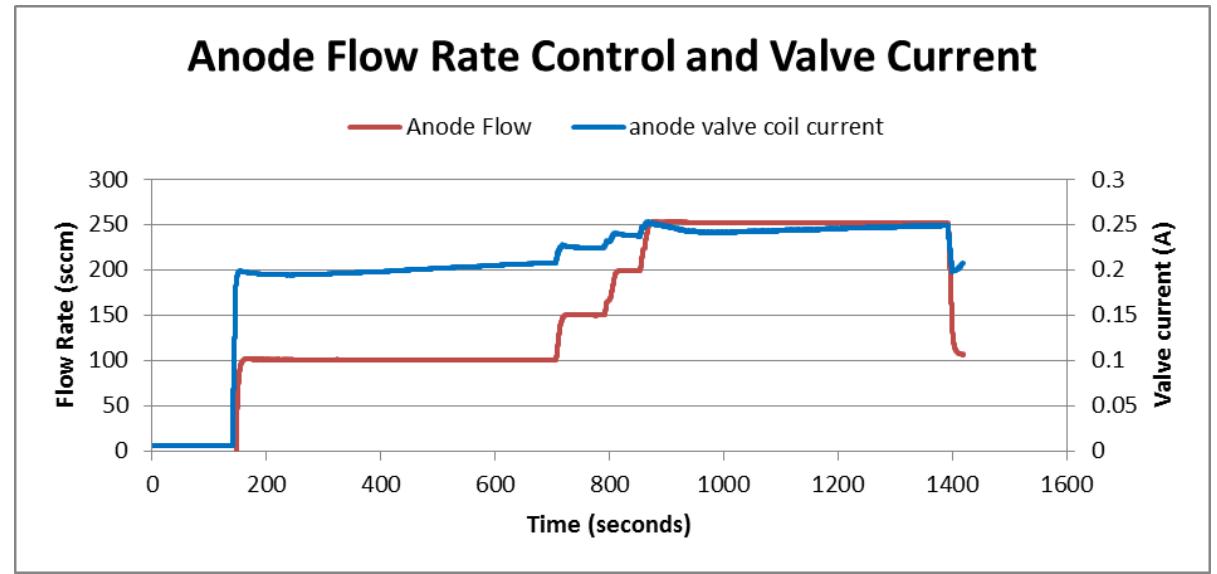

Figure 11. Anode Flow Rate and PFCV current telemetry from SFC, SFC operating the MFC which supplies Xenon to the Nested Hall Thruster inner channel

Reading pressure and delivering a valve current are the hardware tasks assigned to the SFC electronics, but the SFC FPGA contains the logic that orchestrates the flow control system. SFC FPGA contains a digital control system which is capable of adjusting valve position in three modes, open loop valve current mode, closed loop flow rate and closed loop discharge control mode. Controlling the valves by just sending a fixed current command (open loop) would not be a nominal mission operating mode, but it does provide a convenient way to perform system development and hardware verification. During a mission or ground testing, the thruster anode channels will be controlled in discharge current mode and flow rate control mode. The cathode valve will always be controlled in closed loop flow mode. The flexibility of the flow control system gives the EP string various options to operate in. Thruster start up can be done as a soft start by slowly increase gas flow once discharge voltage has already been established. Thruster start up can also be done as a hard start, by first flowing gas to a controlled level and then applying discharge voltage. Once the thruster has started, it can continue to be operated in closed loop flow rate control mode or it can be switched over to discharge current control mode. In discharge current control mode, the anode flow rate is adjusted as needed in order to maintain a constant discharge current which results in a constant thrust. If not operated in this mode, discharge current will vary for a constant flow rate as discharge voltage settings or magnet settings are changed. An example of the SFC performing closed loop discharge control is shown in Figure 12.

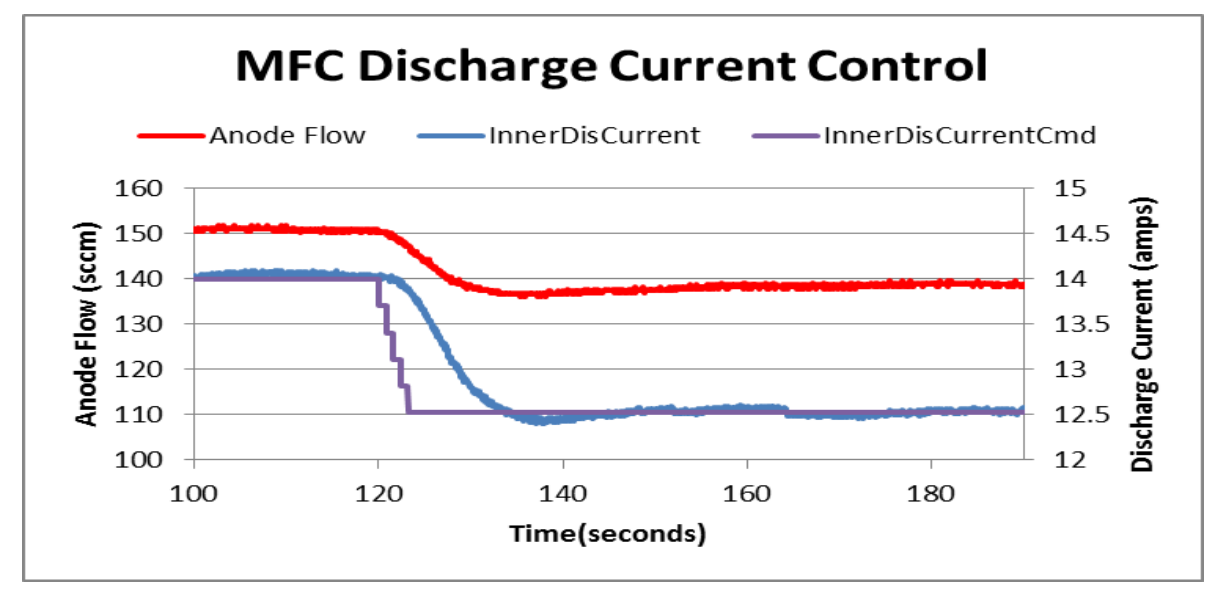

Figure 12. SFC performing closed loop discharge current control with MFC valves. Data is from SFC telemetry. Operation is done on inner channel of the Nested Hall Thruster 
The Nested Hall Thruster has three channels which require different flow rates along with a common cathode. The varying range of required flow rate for each anode channel means that control loop optimization for each channel is different. In addition the PMU valves have different requirements for flow response. Normally this would result in needing multiple control circuits with the same topology, but different component values to account for the different channel properties. However, in the PPU the digital control loop gains can be programmed specifically for each channel and can be updated on the fly through the user interface software or eventually the spacecraft computer. This results in the ability to change control variables with the touch of a button rather than a soldering iron. This has led to extremely fast loop optimization during ground testing when hooking up PPU, MFC and the Nested Hall Thruster together for the first time. Furthermore, the flow rate time constants in the NHT system are slow enough to evaluate through telemetry. If in flight a critical system in the feed system changed such as gas pressure regulator failure, the control loops could be optimized in flight and the mission could not lose performance or in extreme cases not lose functionality.

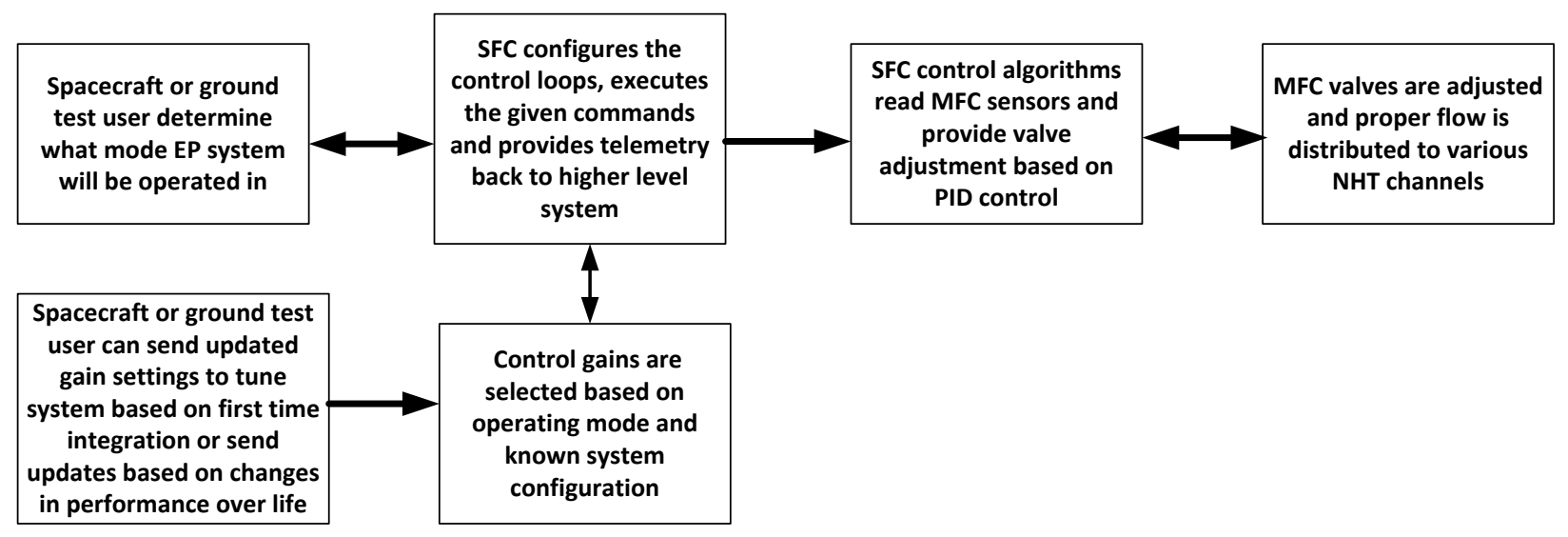

Figure 13- System Flow Controller Firmware Architecture

\section{Conclusion}

Aerojet Rocketdyne has developed a EP architecture which can support the increased power capabilities of Hall Thrusters which will be available for space flight in the near future. The EP architecture developed will allow for the $200 \mathrm{~kW}$ power target to be met with high efficiency and stable control for both PPU and Xenon flow control. This architecture has been demonstrated in incremental steps throughout the two years of development for this program. Components of the system were initially tested individually, then integrated and demonstrated with the Nested Hall Thruster. At the conclusion of the three-year contract Aerojet Rocketdyne plans to have completed a 100 hour 100kW demonstration with the Nested Hall Thruster, PPU, PMU and MFC. The architecture, component design and testing to date have demonstrated that a flight system that can power $200 \mathrm{~kW}$ of Hall Thruster loads is an achievable goal for the near future.

\section{Acknowledgments}

The NextSTEP program team would like to thank the NASA Human Exploration and Operations Mission Directorate, Advanced Exploration Systems Division for their continued support of the work discussed in this paper and all the NextSTEP reviewers, technical consultants and team members at Aerojet Rocketdyne, University of Michigan, NASA JPL, and NASA GRC who have contributed to the success of the program to date. 


\section{References}

[1] NASA, "Next Space Technologies for Exploration Partnerships Broad Agency Announcement NNH15ZCQ001K," Oct. 2014.

[2] J. Jackson, M. Allen, R. Myers, A. Hoskins, E. Soendker, B. Welander, A. Tolentino, S. Hablitzel, S. Hall, A. Gallimore, B. Jorns, R. Hofer, D. Goebel and E. Pencil, "100 kW Nested Hall Thruster System Development," in 35th International Electric Propulsion Conference, Atlanta, GA, 2017.

[3] S. J. Hall, B. A. Jorns, A. D. Gallimore, H. Kamhawi, T. W. Haag, J. A. Mackey, J. H. Gilland, P. Y. Peterson and M. J. Baird, "High-Power Performance of a 100-kW Class Nested Hall Thruster," in 35th International Electric Propulsion Conference, Atlanta, GA, 2017.

[4] R. E. Florenz, A. D. Gallimore and P. Peterson, "Developmental Status of a 100-kW Class Laboratory Nested Channel Hall Thruster," in 32nd International Electric Propulsion Conference, Wiesbaden, Germany, 2011.

[5] S. W.H. Shark, V. Calugaru, A. Tolentino, S. Hablitzel, B. A. Jorns, A. D. Gallimore, E. Pencil and S. J. Hall, " TEST Results From a $10 \mathrm{~kW}$ Demonstration of the XR-100 Hall Propulsion System," in 65th JANNAF Propulsion Meeting, Long Beach, CA, 2018. 